\title{
CONJUNTURA DAS GOVERNANÇAS TURÍSTICAS NO BRASIL NO CONTEXTO DA COVID-19
}

\section{THE CONJECTURE OF THE TOURISM GOVERNANCE IN BRAZIL IN THE SETTING OF THE COVID-19}

\author{
ELAINE JOHN \\ Coordenadora da área de Gestão e Negócios e Humanidades na Universidade Educacional de Santa \\ Catarina (UNISOCIESC) \\ Doutora em Administração e Turismo (UNIVALI) \\ Orcid: https://orcid.org/0000-0003-0224-3607 \\ E-mail: elaine_j8@hotmail.com \\ Rua Alberto Torres, 1580 - Centenário - São Bento do Sul/SC - CEP: 89283-180 \\ MARIANA PIRES VIDAL LÓPEZ \\ Professora Adjunta na Universidade Federal Rural do Rio de Janeiro (UFRRJ) \\ Doutora em Administração e Turismo (UNIVALI) \\ Orcid: https://orcid.org/0000-0002-4835-4866 \\ E-mail: marividal@gmail.com

\section{DAIKO LIMA E SILVA} \\ Professor Substituto do Eixo Tecnológico de Turismo, Hospitalidade e \\ Lazer no Instituto Federal Catarinense - Campus Camboriú (IFC) \\ Turismólogo do Estado de Santa Catarina - SANTUR \\ Mestre em Administração - ESAG/UDESC \\ Orcid: https://orcid.org/0000-0003-4274-6460 \\ E-mail: prof.daiko@gmail.com
}

Submissão: 15/08/2020. Revisão: 10/12/2020. Aceite: 21/12/2020. Publicação: 29/12/2020.

DOI: http://dx.doi.org/10.22277/rgo.v14i1.5757

\section{RESUMO}

A Governança Turística (GT) é considerada uma prática de descentralização da gestão pública, promovendo a participação democrática de diferentes atores, tanto na gestão, como na execução de tarefas, e sua relevância ocorre no contexto mundial quanto nacional. Aliado a isto, o contexto pandêmico causado pela COVID-19 remodelou todas as esferas da sociedade, inclusive do turismo. Há projeções que no setor de turismo os impactos econômicos da COVID19 deverão fazer com que mais de 75 milhões de empregos sejam perdidos e que ocorra um prejuízo de 2,1 trilhões de dólares segundo o World Travel Tourism Council (2020). Neste sentido, este artigo visa analisar a conjuntura das GTs no Brasil no contexto da COVID-19. A metodologia utilizada teve uma abordagem qualitativa de caráter exploratório-descritiva, com técnicas de coleta e análise vinculadas a netnografia. Os resultados apresentaram que apesar do contexto pandêmico da COVID-19 ser prejudicial ao setor turístico, a melhora ecológica é incontestável, fator este muito discutido nas GTs brasileiras, principalmente vinculado ao turismo em massa ou overtourism, o qual deve ser repensado. Além disto, as GTs nacionais se consolidaram como ferramenta efetiva do aumento competitivo, principalmente com a valorização do turismo local, tendência atual e futura neste segmento.

Palavras-chave: COVID-19. Governança Turística. Netnografia. 


\begin{abstract}
The Tourist Governance (GT) is considered a practice of decentralization of the public management, promoting the democratic participation of different actors, both in the management as in the execution of tasks, and its relevance occurs in the global context as national. Coupled to this, the pandemic context caused by the COVID-19 remodeled all the spheres of the society, moreover, the tourism. Global impacts, in this sector, will lose more than 75 million jobs and a damage of 2,1 trillions of dollars according to the World Travel Tourism Council (2020) affecting so many public aspects as social. In this regard, this article aims to analyze the conjecture of the GTs in Brazil in the context of the COVID-19. The used methodology had an investigatory descriptive qualitative character approach, with linked techniques of collection and analysis of the netnography. The results set forth that despite the pandemic context of the COVID-19 to be damaging to the tourist sector, the ecological improvement is indisputable, this factor very much discussed in the Brazilian GTs, mainly linked to the mass tourism or over tourism, which must be rethought. Besides this, the national GTs was consolidated as an effective tool of the competitive increase, mainly in the increase of value of the local tourism, current and future tendency in this segment.
\end{abstract}

Keywords: COVID-19. Tourism Governance. Netnography.

\title{
1 INTRODUÇÃO
}

O setor de turismo, inserido em um cenário marcado pelo progresso tecnológico, com novas configurações de competitividade, práticas de trabalho e mudanças de comportamento dos clientes, busca adaptar-se às novas formas de gestão e compartilhamento de tarefas que vêm surgindo, segundo a United Nations World Tourism Organization (UNWTO, 2011).

Uma dessas novas formas de adaptação diz respeito à Governança Turística (GT), uma organização oficial do turismo, que procura vincular diversos conjuntos de elementos institucionais, responsáveis pela elaboração e operacionalização dos projetos de planejamento e gestão do turismo, através do contato direto com os atores do trade, assegurando a consecução de metas e objetivos coletivos (VIEIRA; COSTA; BOAVENTURA, 2011; FUINI, 2014; QUEIROZ; HORRILLO, 2015; FERNANDEZ; FERNANDEZ, 2017).

A institucionalização de uma GT auxilia no estabelecimento de diretrizes e políticas públicas que visam conduzir o desenvolvimento turístico por meios participativos e inovativos de cada diferente contexto, conectando os desafios, as oportunidades e as reais possibilidades de querer e/ou poder executar determinadas ações dentro do destino turístico (MTUR, 2007; WESLEY; PFORR, 2010). Deste modo, uma GT varia de acordo com o destino, intervenção estatal e da autonomia social (FERNÁNDEZ; FERNÁNDEZ, 2017; STOFFELEN; VANNESTE; 2017).

Tanto no contexto nacional como internacional, reflexões sobre a importância de uma GT vêm sendo discutidas (TRENTIN, 2016; QUEIROZ; HORRILLO, 2015; RODRIGUES; BERNARDO; DOMINGUEZ, 2018; SIAKWAH; MUSAVENGANE; LEONARDO, 2019). Nos estudos de Upadhya (2016) em Governanças Turísticas no Reino Saudita, o autor considerou necessária a ampliação de pesquisas que vinculem formas de valorizar as identidades e tradições de determinada região aliado ao desenvolvimento do trade turístico, vinculando, assim, as características de Governanças Turísticas se fazem necessário tanto no seu escopo teórico como no empírico. Já Luthe e Wyss (2016), ao analisarem as Governanças Turísticas nos Alpes Suíços, apontaram a necessidade de mais estudos relacionados a essa temática. Esse fator também foi explicitado por Stoffelen e Vanneste (2017), que apresentaram estudos 
relacionados as características de Governanças Turísticas alemãs e tchecas, assim como, Siakwah et al. (2019) estudaram as GTs na África e apontaram lacunas de pesquisa nesta temática.

A importância de estudos vinculados as GTs também foram mencionadas por artigos nacionais como de Conceição (2020), sobre Governanças Turísticas da Costa Verde e Mar/SC, Região das Hortências/RS e Costa das Dunas/RN, e Bárcia (2020) aplicando sua pesquisa na GT de Búzios. Assim, recomenda-se que a GT esteja na agenda de estudos do setor turístico como um relevante meio de novas perspectivas de coordenação, colaboração e cooperação dos atores, gerando estruturas baseadas na necessidade de inovar e fortalecendo os esforços de diferentes atores no turismo (UPADHYA, 2016; JAMAL; CAMARGO, 2018; GENG et al., 2020).

Uma inovação disruptiva atingindo tanto o turismo nacional quanto o internacional, diz respeito ao contexto pandêmico causado pela COVID-19. Com o surgimento deste vírus, houve uma certa desestruturação do setor do turismo, fazendo com que grande parte das atividades ligadas a este segmento fossem suspensas e paralisadas (LAZZARINI; MUSACCHIO, 2020).

Por exemplo, em março de 2020, mais de $90 \%$ da população mundial possuía restrições de viagens e muitos destinos turísticos encontravam-se vazios (HALL, et al. 2020). Observando o contexto nacional, temos uma estimativa de perdas para o turismo (comparado ao PIB de 2019) na ordem de aproximadamente 116,7 bilhões de reais, o que representa $21,5 \%$ na produção total para o período do biênio 2020-2021 (FGV, 2020).

Dados os reflexos da COVID-19 no âmbito global, e a importância das Governanças Turísticas no âmbito deste segmento, este artigo visa analisar a conjuntura das Governanças Turísticas no Brasil no contexto da COVID-19.

Neste aspecto, este estudo busca fazer com que a análise das GTs no contexto brasileiro pandêmico da COVID-19 possa contribuir de forma efetiva para evolução teórica acerca desta temática, assim como, agregar informações empíricas para que uma transformação crescente e positiva no turismo nacional possa ocorrer neste cenário.

\section{GOVERNANÇA TURÍSTICA E COVID-19: ASPECTOS GERAIS}

A Governança Turística é uma prática de governo que visa dirigir efetivamente os setores do turismo, para que o trabalho ocorra de forma coordenada, colaborativa e/ou cooperativa, buscando sempre a eficiência e transparência, para o alcance de metas de interesse coletivo (UNWTO, 2011; DURAN, 2013; FERNÁNDEZ; FERNÁNDEZ, 2017). Sua essência está baseada em políticas de regionalização do turismo, a qual apresentava uma articulação entre todos os atores de um trade turístico (stakeholders), para a busca de soluções e o desenvolvimento competitivo de modo coletivo (FERNANDES; CORIOLANO, 2015; WAN; BRAMWELL, 2015). Seus processos são baseados na decisão público-privada e buscam avançar as políticas públicas voltadas ao turismo, com um movimento de descentralização do processo decisório, através de formas mais flexíveis de gestão e regulação (VELASCO, 2007; TOMIO; SCHMIDT, 2014).

Observado o contexto nacional, vemos o marco inicial da GT através dos esforços de políticas públicas de empowerment dos municípios e regiões turísticas, o qual buscava fomentar a qualidade e na quantidade de empreendimentos do turismo brasileiro (TRIGO; MAZARO, 2012). O Ministério do Turismo (MTUR) iniciou, em 1994, a orientação para uma gestão descentralizada, com ações voltadas para a municipalização, por meio do Programa Nacional de Municipalização do Turismo, que orientou posteriormente, as diretrizes para o 
Programa de Regionalização do Turismo, criado em 2004 (RODRIGUES; SOUZA, 2016). Estes programas disponibilizaram informações sobre como organizar a gestão do turismo em escala municipal e regional, porém, sem dispor de muitas ações concretas para implementá-las, o que foi retificado posteriormente, com os programas de instituição da GT e das IGRTs pelo MTUR em 2007 (TRENTIN, 2016).

Cabe salientar, que este movimento vem ocorrendo não somente no Brasil, mas em todo o mundo, com formas de descentralização da gestão turística que incentivam os governos a repassarem, aos atores locais, a autonomia, para trabalharem em conjunto para que o desenvolvimento turístico regional aconteça (RODRIGUES; SOUZA, 2015). Deste modo, observa-se que uma GT possui uma combinação institucional multiescalar, que integra todos os stakeholders, através de um processo lento e gradual, com diversas ações e programas de aprendizado, tanto para a introdução como no desenvolvimento contínuo, a qual busca o sucesso do trade turístico (FERNÁNDEZ; FERNÁNDEZ, 2017; STOFFELEN; VANNESTE; 2017).

Além de tais aspectos, a integração deve ser transparente e responsável, buscando interesses coletivos que são compartilhados entre todos os atores, impactando e estimulando o setor turístico a desenvolver soluções e aproveitar as oportunidades com base em acordos que reconheçam a todos os envolvidos (DURAN, 2013; CONCEIÇÃO, 2020). Neste sentido, o trabalho integrado gera impactos e aumenta a estratégia competitiva para o trabalho turístico em diferentes regiões (FUINI, 2014; ESTOL; FONT, 2016; SIAKWAH et al. 2019).

Observando o turismo em diferentes regiões, aponta-se que a GT deve estar também vinculada as políticas públicas vigentes tentando sanar os problemas de alta complexidade de gestão dos destinos turísticos, e sendo assim responsáveis, por tentar satisfazer as necessidades de seus integrantes com a participação de todos os envolvidos no planejamento, execução e avaliação das políticas turísticas (HUBNER; PHONG; CHÂU, 2014; QUEIROZ; HORRILLO, 2015).

Analisar uma GT também diz respeito a analisar o poder e a política pública envolvida no sistema de desenvolvimento turístico de determinada região, e assim, compreender que desafios possam ser superados e novas oportunidades poderão ocorrer (WESLEY; PFORR, 2010; HUBNER et al. 2014). Cabe ainda salientar, que as políticas públicas voltadas ao turismo devem ser elaboradas e executadas por todos os stakeholders envolvidos no trade, visto que há diferentes realidades, competências e aspectos que devem ser considerados e valorizados (MILLER et al., 2010; ESTOL; FONT, 2016). Assim, deve ser considerada a necessidade de sensibilização dos gestores para que as políticas públicas possam ser desenvolvidas em conjunto, apresentando soluções efetivas para o turismo em médio e longo prazo, visando uma sociedade mais democrática, justa e equilibrada (MILLER et al., 2010; BERNARDO, 2015; ESTOL; FONT, 2016).

Estes aspectos, vinculados às políticas públicas no turismo, também podem ser visualizadas no contexto vinculado a pandemia da COVID-19. Segundo a Organização Mundial do Turismo (OMT, 2020), o turismo é o setor econômico mais afetado na crise da COVID-19, e diversos países como Itália, França, Alemanha e Nova Zelândia fecharam suas fronteiras nacionais e internacionais (por tempos determinados), desencadeando suspensões e reduções de voos nacionais e internacionais, como nunca vivenciados na história.

\subsection{PRINCÍPIOS, DIMENSÕES E DELIMITAÇÕES DA GOVERNANÇA TURÍSTICA FRENTE AO COVID-19}

A consolidação efetiva de uma GT depende, de um legítimo reconhecimento de todos os stakeholders envolvidos e do estabelecimento básico da confiança entre estes 
(ROBERTSON, 2011; GONZÁLEZ, 2014). O ponto de partida da instalação de uma GT, deverão ser, as definições claras a respeito de quais são seus atores (públicos, privados e não governamentais) e quais atividades desenvolverão (QUEIROZ; HORRILLO, 2015, VALENTE; DREDGE; LOHMANN, 2015). Kalbaska et al. (2017) detalham que, entre atores públicos, privados e não governamentais, seis grupos de stakeholders são primordiais: os governos, as empresas com fins lucrativos, as sem fins lucrativos (inclusive institutos de pesquisa), cidadãos, turistas e empregados (muitas vezes representados por seus sindicatos).

Dessa forma, para que ocorra cooperação entre os atores de uma GT, as tomadas de decisões e relações de poder devem ser equilibradas (PECHLANER; VOLGGER; HERNTREI, 2012; HUBNER et al., 2014; FERNANDES; CORIOLANO, 2015). Os elementos estratégicos, tanto em nível nacional quanto estadual, dependerão da execução dos processos regionalizados, que produzem reflexos em todo o contexto inserido. Assim, o planejamento espacial deve ser pensado visando a articulação material e social, de forma a se agregar diferentes esferas de poder, que não poderão ser rejeitadas (RODRIGUES; SOUZA, 2015).

Neste sentido, seis princípios fundamentais, segundo o levantamento bibliográfico efetuado por Tomio e Schmidt (2014), visam delinear e fortalecer uma GT. São eles: a integridade, a busca de equidade e proteção igualitária dos atores, visão e liderança, desenvolvimento de conhecimento e partilha de experiências, clareza de papéis e responsabilidades, além de transparência e prestação de contas.

Ressalta-se que esses princípios visam direcionar uma GT, mas é prioritário inicialmente, planejar coletivamente a melhor forma de se iniciar esse processo, pois somente assim, poderão ser alcançadas a credibilidade e confiabilidade integrada, segundo Tomio e Schmidt (2014). Todavia, a falta de meios confiáveis e integrados influencia as relações dos atores em um trade (inclusive de poder) e pode afetar sensivelmente a eficácia do desenvolvimento de uma GT (WESLEY; PFORR, 2010; TRENTIN, 2016; VELASCO, 2016).

Nesse aspecto, também se torna necessário, definir as dimensões e delimitações de uma GT, bem como os fatores fundamentais para que esta exista (QUEIROZ; HORRILLO, 2015). Quando observadas as dimensões e delimitações no processo de implantação e manutenção de uma GT de forma eficiente, são visualizados aspectos no Quadro 1, segundo o levantamento teórico efetuado por Queiroz e Horrillo (2015).

Quadro 1 - Dimensões e delimitações da Governança Turística

\begin{tabular}{|l|l|l|}
\hline Dimensões & \multicolumn{1}{|c|}{ Delimitação } & \multicolumn{1}{c|}{ Fatores } \\
\hline Quem? & $\begin{array}{l}\text { - Identificação de atores } \\
\text { - Participação da variedade de atores }\end{array}$ & $\begin{array}{l}\text { - Legitimidade e representatividade } \\
\text { - Capacidade para motivar } \\
\text { - Metas coletivas }\end{array}$ \\
\hline Que? & $\begin{array}{l}\text { - Segundo áreas de atividade } \\
\text { - Segundo participação no processo de } \\
\text { decisão }\end{array}$ & $\begin{array}{l}\text { - Formação } \\
\text { - Compromisso } \\
\text { - Recursos financeiros/tecnológicos } \\
\text { - Tempo para participar }\end{array}$ \\
\hline Como? & - Transparência e apresentação de contas & $\begin{array}{l}\text { - Respeito às regras } \\
\text { - Mecanismos de controle e sanções } \\
\text { - Website, fóruns } \\
\text { - Calendário anual de atividades }\end{array}$ \\
\hline
\end{tabular}

Fonte: adaptado de Queiroz e Horrillo (2015).

Segundo o estudo apresentado por Queiroz e Horrillo (2015), deve-se identificar as partes interessadas na GT, quais recursos e capacidades são determinantes para a participação dos atores do trade nos processos de gestão, quais regras e instrumentos favorecem a participação e resoluções de problemas, para somente após de tais aspectos, 
definir quais as melhores formas de se trabalhar.

Com as dimensões e delimitações bem definidas, uma GT trabalha de forma conjunta, envolvendo a pluralidade de atores, através de um desenho dos processos de gestão previamente acordados e com desenvolvimento coletivo, tanto público como privado (GONZÁLEZ, 2014). Esses processos melhoram a gestão dos conflitos e avançam as políticas públicas voltadas ao turismo (VELASCO, 2007).

Sobre a gestão de conflitos coletivos, é importante ressaltar que, caso estes ocorram, necessitam ser administrados de maneira consciente, primeiramente assumindo sua existência, e posteriormente definindo os maiores problemas gerados através de tais conflitos, para então serem abordados e solucionados/minimizados através de instrumentos eficazes dentro de uma GT (HARGUINDÉGUY, 2013). Ter consciência da gestão de conflitos, orientando as atividades para resolução dos mesmos, através de meios e técnicas bem alinhadas, faz com que a estrutura institucional da GT seja fortalecida (GONZÁLEZ, 2014).

Esta mudança no processo democrático pode gerar ações públicas mais condizentes com as expectativas da sociedade e, em especial, dos stakeholders dentro de uma GT, além de possivelmente gerar inovações dentro de sistemas ecoinovativos, capazes de uma maior eficácia competitiva. Então, a ideia básica em uma GT é aquela que vincula o aumento do grau de cooperação e aprofunda as relações de interação entre os atores, dando poder e autonomia para enfrentar os desafios competitivos dentro do setor turístico, de modo inovativo e sustentável (GONZÁLEZ, 2014).

Neste aspecto, torna-se possível afirmar que a GT é uma ferramenta fundamental para os atuais desafios competitivos frente ao contexto pandêmico do Coronavírus. Como ressalta Hall, Scott e Gossling (2020), a natureza seletiva dos efeitos da COVID-19 e as medidas para contê-la poderão levar a uma reorientação do setor turístico, contribuindo em alguns casos, inclusive, para políticas protecionistas e nacionalistas, no entanto, a necessidade e possibilidade de transformação de forma macro do turismo é evidente, especificamente vinculada ao turismo sustentável, com uma nova e mais clara abordagem global. Este turismo sustentável, visa transformar o turismo global requerendo um maior compromisso, entre as organizações turísticas nacionais e internacionais e ao sistema turístico como um todo.

\section{METODOLOGIA DA PESQUISA}

Uma pesquisa é um conjunto de processos sistemáticos, críticos e empíricos aplicados ao estudo de um fenômeno (SAMPIERI; CALLADO; LUCIO, 2013). Nesse aspecto, este estudo buscou vincular, de forma sistemática, uma análise sobre a conjuntura das GTs no Brasil no contexto da COVID-19. Para que este conhecimento da realidade fosse alcançado, o delineamento desta pesquisa científica foi fundamental, de modo que ocorresse um direcionamento exato entre o que se desejava pesquisar e o que seria possível alcançar.

Desse modo, utilizou-se uma abordagem qualitativa, que permitiu a realização de estudos aprofundados sobre uma ampla variedade de tópicos (YIN, 2015). Os procedimentos centrais da abordagem qualitativa, segundo Flick (2009), diferem dos empregados nas pesquisas quantitativas, pois consistem na escolha correta de métodos e teorias oportunas, no reconhecimento e na análise de diferentes perspectivas e nas reflexões dos pesquisadores vinculados ao campo estudado, neste caso, as Governanças Turísticas Brasileiras no contexto da COVID-19.

Tratou-se também de uma pesquisa exploratório-descritiva, uma vez que esse tipo de estudo aponta as características de determinada população e determinado contexto, relacionando-as com as categorias de análise e definindo sua natureza (VERGARA, 2000). 
A coleta e a análise dos dados foram efetuadas através da netnografia, que é uma forma especializada de etnografia utilizando comunicações mediadas por computador/celulares, a qual permite que se investigue a realidade por dentro de um grupo no ambiente virtual, gerando conhecimento científico a partir da interpretação do pesquisador acerca do ponto de vista dos investigados (CORREIA, ALPERSTEDT E FEUERSCHUTTE, 2017). Segundo Kozinets (2014), com a netnografia tem-se a possibilidade de encurtar as distâncias entre tempo e espaço devido à própria dinâmica da internet e dos grupamentos sociais dispostos na rede e nos dispositivos associados a ela. O espaço virtual pode ser acessado de qualquer local onde haja acesso à internet, além da grande quantidade de informações possíveis de se coletar, sendo esta uma vantagem para o pesquisador (SADEBECK, 2004).

Neste aspecto inicialmente, foram efetuados os levantamentos teóricos dos conceitos a serem estudados e analisados neste estudo, e posteriormente observado as lives via YouTube no dia 10/04/2020 e do dia 13/04/2020. Os conceitos que mais se repetiam, foram apontados como as três proxies de estudo. Proxies, são utilizadas para captar determinados fenômenos, efetuando-se um tratamento tangencial ao redor dos conceitos afins, para que se possa ter maior confiança nos resultados obtidos (LOPES, 2012).

Deste modo, as proxies inicialmente puderam apontar os principais tópicos vinculados a pesquisa: Princípios, Dimensões e Delimitações da GT na COVID-19. Após estes tópicos serem definidos, foram submetidos a 3 informantes-chave para sua validação. Os "informantes-chave", são experts na área, que revisaram os tópicos encontrados, validando os mesmos, e assim os tornando construtos da pesquisa, para que se tornem as categorias de análise do estudo (YIN, 2016).

A informante-chave 1 é Bacharel em Administração pela Universidade Federal de Santa Catarina (UFSC), Doutora em Administração e Turismo pela Universidade do Vale do Itajaí (UNIVALI), com mais de 20 anos de prática nesta área, sendo atualmente, professora adjunta no curso de Administração na Universidade Federal de Sergipe (UFS). A informante- chave 2 é Mestre pelo Programa de Pós-Graduação em Turismo da Universidade Federal Fluminense (UFF), Especialista em Turismo, Meio Ambiente e Negócios pela Universidade Estácio de Sá (UNESA), com vasta experiência profissional na área do Turismo. A informante-chave 3 é graduada em Ciências Contábeis pela Universidade do Contestado (UNC) e Doutora em Administração e Turismo (com dupla titulação) pela UNIVALI e Universidad de Alicante (Espanha), tendo mais de 10 anos de experiência em estudos focados em cidades inteligentes, atualmente sendo docente do Centro Universitário Avantis (UNIAVAN).

Após as análises efetuadas pelas informantes-chave, apontaram-se as considerações a serem agregadas (em vermelho) gerando assim, os construtos finais que deveriam ser analisadas nesta pesquisa. Foram eles: Princípios, Dimensões e Delimitações (objetivando questões relacionadas ao incentivo do turismo interno) das GTs no Brasil no contexto da COVID-19.

Definidos os construtos, iniciaram as coletas de dados, inicialmente através de observações participantes, baseadas nos estudos de Verdú et al. (2015), os quais mencionam que o rol do investigador pode ser oculto (passiva/encoberta) ou não oculto (moderada/ativa). Neste aspecto foram efetuadas 13 observações participantes conforme Quadro 2. 
Elaine John, Mariana Pires Vidal López e Daiko Lima E Silva

Quadro 2 - Dados das Observações Participantes

\begin{tabular}{|c|c|c|c|}
\hline Sigla & Duração aproximada & $\begin{array}{c}\text { Grau da participação (rol do } \\
\text { investigador) }\end{array}$ & Datas das Lives via Youtube \\
\hline OBS. A & 1 hora & Participante passivo (oculto) & $10 / 04 / 20$ vespertino \\
\hline OBS. B & 1 hora & Participante passivo (oculto) & $10 / 04 / 20$ noturna \\
\hline OBS. C & 1 hora & Participante passivo (oculto) & $13 / 04 / 20$ \\
\hline OBS. D & 1 hora & Participante passivo (oculto) & $14 / 04 / 20$ matutina 1 \\
\hline OBS. E & 1 hora & Participante ativo (não oculto) & $14 / 04 / 20$ matutina 2 \\
\hline OBS. F & 1 hora & Participação passivo (oculto) & $14 / 04 / 20$ noturna \\
\hline OBS. G & 1 hora & Participante passivo (oculto) & $15 / 04 / 20$ vespertina \\
\hline OBS. H & 1 hora & Participante passivo (oculto) & $15 / 04 / 20$ noturno \\
\hline OBS. I & 1 hora & Participante ativo (não oculto) & $21 / 04 / 20$ matutina 1 \\
\hline OBS. J & 1 hora & Participante passivo (oculto) & $21 / 04 / 20$ matutina 2 \\
\hline OBS. K & 1 hora & Participante ativo (não oculto) & $21 / 04 / 20$ noturno \\
\hline OBS. L & 1 hora & Participante passivo (oculto) & $24 / 04 / 20$ \\
\hline OBS. M & 1 hora & Participante passivo (oculto) & $25 / 04 / 20$ \\
\hline
\end{tabular}

Fonte: elaborado pelos autores (2020).

Na observação $A, B, C, D, F, G, H, J$, L e M como já mencionado, optou-se por uma investigação passiva oculta. Já no caso das observações $\mathrm{E}, \mathrm{I}, \mathrm{e} \mathrm{K}$, como as lives eram com atores do trade turístico em menor número, foi necessária a apresentação do pesquisador (caracterizando, deste modo, uma participação ativa não oculta) pois, esta foi uma das condições sugeridas para sua participação. Ainda que os sujeitos da pesquisa soubessem que estavam sendo observados, em momento algum notou-se qualquer tipo de retaliação ou omissão de informações, ao contrário, por diversas vezes notou-se a sua necessidade de falar e abordar temas polêmicos, até mesmo como forma de "desabafos".

Em um segundo momento, foram efetuadas entrevistas semiestruturadas com cinco especialistas na área. Richardson (2008) aconselha que as entrevistas semiestruturadas sejam guiadas de forma que o entrevistado esteja à vontade, para que o entrevistador possa aprofundar os temas que considere fundamentais. O perfil dos entrevistados, assim como sua forma de coleta podem ser encontrados no quadro 3.

Quadro 3 - Perfil dos Entrevistados

\begin{tabular}{|c|c|c|c|}
\hline Sigla & Perfil dos entrevistados & Forma de Coleta & $\begin{array}{c}\text { Tempo de atuação no } \\
\text { turismo }\end{array}$ \\
\hline Entrevistado 1 & Professora Substituta IFSC & WhatsApp & 25 anos \\
\hline Entrevistado 2 & Consultora Nacional de Turismo & Direct Instagram & 18 anos \\
\hline Entrevistado 3 & Professora Efetiva de Turismo UFRN & WhatsApp & 22 anos \\
\hline Entrevistado 4 & Superintende de Turismo Municipal & WhatsApp & 25 anos \\
\hline Entrevistado 5 & Membro Conselho Municipal de Turismo & WhatsApp & 23 anos \\
\hline
\end{tabular}

Fonte: Elaborado pelos autores (2020).

Como última forma de coleta foram efetuados levantamentos digitais junto ao Instagram Oficial do Ministério do Turismo do Brasil, no qual constava um total de 8.309 postagens em 29 de junho de 2020, sendo selecionadas postagens relacionadas à COVID-19, um total de 18 publicações. Estas foram classificadas por ordem de data de postagem, sendo a postagem MTUR 1, a primeira postagem relacionada ao tema COVID-19, e a postagem MTUR 18, a última postagem relacionada a esta temática. Cabe salientar, que uma grande limitação deste estudo foi o curto espaço de tempo de observação e coleta de dados (abril de 2020 até julho de 2020) devido ao recente contexto da COVID-19 no Brasil. 


\section{ANÁLISE DOS RESULTADOS}

No fim do ano de 2019, um surto epidêmico ocorreu na cidade de Wuhan província de Hubei, China. O número considerável de pessoas acometidas por pneumonia levou a Comissão de Saúde Municipal de Wuhan a emitir um alerta acionando a Organização Mundial de Saúde em 31 de dezembro de 2019. Já em 7 de fevereiro de 2020, foi sequenciado um novo Coronavírus denominado Sars-CoV-2, que gera a doença que ficou conhecida como COVID-19, já haviam sido sequenciados até o ano de 2019, 6 genomas de Coronavírus que causaram epidemias no passado. Contudo, este vírus resulta num quadro mais grave ao paciente, seu contágio também é mais ágil levando uma porcentagem dos enfermos ao óbito. Esta situação exigiu medidas governamentais dos líderes mundiais para conter a doença e resguardar o sistema de saúde dos países.

Os vírus SARS-CoV e MERS-CoV causaram epidemias no passado, assim como a COVID19 causa agora (2020). Porém, todos eles possuem muitas similaridades em relação a transmissão e sintomas. Uma importante característica que difere esses vírus é que a COVID19 possui uma larga porcentagem de pessoas assintomáticas, possibilitando o fácil alastramento desta epidemia, com maior facilidade e com alcance maior. Há também a similaridade dos sintomas com outras doenças do trato respiratório, como gripes, resfriados, pneumonia, o que torna difícil o diagnóstico para os médicos, e aumenta ainda mais a periculosidade, se feito uma conclusão equivocada (CASCELLA et al., 2020). Croda e Garcia (2020) salientam que:

Coronavírus da síndrome respiratória aguda grave (SARS-CoV) e Coronavírus da síndrome respiratória do Oriente Médio (MERS-CoV) -, o SARS-COV-2 é um vírus transmitido de humano para humano e capaz de causar doença respiratória grave; contudo, ele se distingue pela capacidade de transmissão a partir de casos assintomáticos, fato que, somado à existência de uma proporção todavia desconhecida de doentes que não desenvolvem manifestações graves da doença, são fatores que afetam a capacidade de contenção da propagação do vírus.

Com a evolução da epidemia na China e o surgimento de novos casos em outros países, a Organização Mundial de Saúde (OMS) decretou em 11 de março de 2020, situação de pandemia. Nesse momento, existiam mais de 118.000 casos em 114 países e 4.291 mortes (OMS, 2020). A Europa Ocidental se tornava o novo epicentro da pandemia, a Itália registrava nessa data, 12.462 casos confirmados e 827 mortes (UOL, 2020) e a Espanha 4.200 casos confirmados e 120 mortes (NYC TIMES, 2020).

O primeiro caso no Brasil foi detectado no dia 26 de fevereiro de 2020 na cidade de São Paulo (Brasil, 2020), era um paciente que havia viajado para a Itália, fato que ilustra o papel do turismo no contexto de disseminação da pandemia. A partir do momento que o vírus chegou ao Brasil, rapidamente se alastrou para outras capitais, fazendo com que alguns sistemas de saúde entrassem em colapso. Como foi mencionado na OBS C:

Enquanto não se tem medicamento, vacina e nem leitos para atender a população que precisará de hospitalização, a medida de distanciamento social se tornou necessária para reduzir o ritmo de contágio e achatar a curva a fim de ganhar tempo para a ampliação de testes, desenvolvimento de vacinas e medicamentos, identificação dos doentes, monitoramento para escolha de medidas mais apropriadas de distanciamento social, adaptação de instalações, produção de equipamentos (respiradores, por exemplo), entre outros.

É difícil mensurar a quantidade total de casos existentes, visto que, durante a realização desta pesquisa, a pandemia está em curso. Contudo, estima-se que milhares de 
pessoas já foram infectadas pelo Coronavírus. Porém, alguns países lideram a quantidade de casos e mortes respectivamente, como: Estado Unidos, Brasil, Rússia, Índia, Reino Unido (OMS, 2020). O fato é que todo este aspecto de distanciamento social gerou uma paralização nas atividades turísticas mundiais, afetando fortemente o setor. Conforme relatado na OBS F: "O impacto da pandemia no setor de serviços ( 3 o setor) é enorme, até mesmo superior ao que foi experimentado na II Guerra Mundial". O fechamento das fronteiras, somado ao impedimento das pessoas viajarem, impactaram fortemente o Turismo, havendo a paralização do setor do Turismo, que engloba: meios de transportes, agências de viagens, meios de hospedagem, entretenimento, entre outros atores. Para mitigar estes impactos negativos, os empresários terão que ter muita resiliência. Pois, o COVID-19 impactou toda a economia, fazendo com que a retomada do setor seja lenta (Entrevistado 4, 5, OBS E e OBS L).

$\mathrm{O}$ entrevistado 3 corrobora com o aspecto anteriormente citado e menciona que, "todavia, neste momento, é possível avaliar os terríveis impactos sociais que a COVID-19 vem causando, principalmente se observado o alto número de mortes no mundo todo". O impacto da pandemia realmente é devastador, tanto economicamente quanto socialmente.

No Brasil, através da Medida Provisória 936, o governo federal destinou cerca de R\$ 51 bilhões para a manutenção de empregos no setor turístico durante a pandemia da COVID19 (postagem MTUR 5). Recursos estes, que somado a outras medidas de enfrentamento, buscam auxiliar empresas do setor a sobreviver em meio à queda brusca em suas respectivas demandas. Caracteriza-se neste aspecto o princípio da proteção igualitária aos atores, segundo Tomio e Schmidt (2014) esta proteção inclusive deve ocorrer pelos que possuem menor poder de negociação perante seus pares, tanto pelo tamanho, quanto importância de seu empreendimento no segmento turístico. Sendo necessário desenvolver formas de proporcionar a esses atores os mesmos benefícios auferidos aos atores com maior poder de negociação.

Conforme relatado pelo entrevistado 5, "toda a cadeia produtiva do turismo brasileiro foi afetada, muitas empresas fecharam, houve desemprego, então para que as pessoas voltem a viajar, a atividade passará por todo um processo de reequilíbrio". Tal aspecto também foi corroborado pelo entrevistado 3, que apontou "mesmo que esta crise atual seja superada ou estabilizada, têm-se que pensar em novas situações e novos vírus que tendem a surgir".

Neste sentido, o período pós pandemia tem uma prospecção de difícil visualização, segundo recentes estudos da Fundação Getúlio Vargas (FGV, 2020), sendo que o prazo de recuperação do setor pode variar entre 12 e 18 meses. Neste sentido, acredita-se que a "Governança Turística tenha papel fundamental no contexto Pós COVID-19" (OBS I). O fortalecimento da Governança Turística, com ênfase às parcerias entre o público, o privado e o terceiro setor será necessária mais do que nunca. Sendo, neste momento fundamental que políticas públicas de turismo se efetivem estando alinhadas por meio da Governança Turística. "O poder público precisa dialogar com o trade e o terceiro setor" (Entrevistado 1 e OBS A).

A GT sempre deve procurar vincular diversos conjuntos de elementos institucionais e representativos, responsáveis pela elaboração e operacionalização dos projetos de planejamento e gestão do turismo, através do contato direto entre atores do trade, assegurando a consecução de metas e objetivos coletivos (VIEIRA; COSTA; BOAVENTURA, 2011; FUINI, 2014; QUEIROZ; HORRILLO, 2015; FERNANDEZ; FERNANDEZ, 2017). Neste aspecto as GTs brasileiras devem se planejar, procurando conhecerem seus verdadeiros DNA's, para assim, formatar seus produtos e promovê-los adequadamente nos melhores canais e com as melhores estratégias. O trade turístico terá que se reinventar, fazendo uso de resiliência e governança na busca de soluções à crise. Porém, é essencial que o problema seja 
enfrentado de forma conjunta e consciente, por meio da identificação e do engajamento de atores, articulando suas ações via Governança Turística (Entrevistado 1, 3, OBS C e OBS F).

A quebra de paradigmas e o aperfeiçoamento do diálogo são fundamentais, neste momento a falta de diálogo entre os poderes executivo e legislativo gera a desregulamentação do setor, refletindo-se em uma série de conflitos e impactos negativos (OBS A, I e L). É fundamental que as políticas públicas agora sejam focadas nas necessidades geradas pela pandemia, conforme as necessidades de cada local. Por exemplo, destinos consolidados precisam ter ações diferentes daquelas dirigidas a Destinos que se encontravam em fase inicial de desenvolvimento (Entrevistado 3 e 5). Os atores coletivos necessitam ter claramente definido o conjunto de valores e objetivos da organização, como resultado de um processo de visão e até mesmo de um plano de ação estruturado conforme apontado por Tomio e Schmidt (2014).

Neste aspecto, vemos as particularidades de cada GT no Brasil, que deve ser visualizada de forma distinta e direcionada, com a participação da variedade de atores como apontado por Queiroz e Horillo (2015), principalmente quando observado o aspecto das políticas públicas estaduais e municipais. Ao observar a postura do governo federal frente a pandemia, salienta-se que "precisam focar em incentivos fiscais, financiamentos subsidiados, tudo para auxiliar que as empresas não fechem suas portas (Entrevistado 5)".

Ao longo do tempo, o governo federal e estadual brasileiro vêm implementando políticas públicas de turismo baseadas na descontinuidade e na troca constante dos gestores e suas equipes. Porém, no caso da pandemia da COVID-19, são eles que vêm sendo os protagonistas na gestão, e os municípios deverão assumir seus respectivos papéis como protagonistas na gestão dos negócios a partir de agora, ainda mais, considerando o novo período de gestão municipal que se iniciará com o processo de eleições municipais que se aproxima (OBS D).

As políticas públicas precisam focar em campanhas publicitárias para conscientizar as pessoas sobre a segurança de viajar. Pois, a regulação e o controle são essenciais ao futuro do turismo (Entrevistado 5 e OBS L). Segundo os entrevistados 1, 2, 4 e 5, "a normatização e a segurança impactarão a imagem do destino e a decisão de compra, pois ele somente viajará ao se sentir seguro. $O$ investimento em experiências, qualificação dos serviços, TIC, inovação, segmentação e na gestão de informações serão essenciais ao planejamento, controle e previsão de outras crises". Neste aspecto, confirma-se o que foi apontado por Queiroz e Horillo (2015) afirmando a importância de recursos financeiros e tecnológicos para as dimensões e delimitações de uma GT. Neste aspecto, também apontou-se a delimitação voltada a normatização onde o governo brasileiro criou um selo denominado "Turismo Responsável, Limpo e Seguro" para que os turistas fiquem atentos à segurança e higiene dos locais, fazendo com que o setor tenha uma normatização padrão, fundamentada em protocolos padrões postagem MTUR 18, 17. "Para ter acesso ao selo é preciso estar inscrito no Cadastur" postagem MTUR 16.

Com este selo pretende-se orientar os empresários, e garantir aos turistas, que as normas básicas para evitar a contaminação pela COVID-19 estão sendo cumpridas. Percebese, por exemplo, um relativo destaque a imagem do destino, sua segurança, higiene e limpeza, visando a não contaminação, fatores considerados importantes ao enfrentamento da crise atual pelos empresários do setor (OBS K). Os gestores das GTs precisam ter como foco de atuação o cidadão, o morador local, procurando incentivar o aperfeiçoamento das áreas de lazer, dos atrativos, parques, praças, entre outras áreas de uso comum, com ênfase a segmentos como Ecoturismo, Turismo de Aventura, Turismo Náutico, Turismo Rural, entre 
outras áreas, com semelhante vocação à natureza, as quais tendem a se recuperar neste primeiro momento (Entrevistado 1).

O impacto da COVID-19 resultará em uma mudança no perfil do consumidor que irá buscar destinos mais baratos, seguros e próximos, que valorizem a experiência e a personalização dos serviços. Fato que trará uma maior maturidade em relação a quem oferta e quem consome. Uma maior consciência no uso dos recursos de ambos também (Entrevistado 2). Neste aspecto o turismo local passará a ganhar cada vez maior relevância de mercado. Tende a ocorrer a valorização do mercado interno, alinhada a um número menor de viagens, que se darão por um tempo maior (número de dias/permanência média), com destaque ao Turismo de Experiência (OBS F). Isto corrobora ao que foi apontado por Queiroz e Horillo (2015) que mencionando que novas áreas de atividades turísticas poderão surgir em uma GT. Neste aspecto destaca-se que a tendência de Turismo Local se deve também por questões de restrições econômicas, geradas pela perda do poder aquisitivo devido à recessão que se apresenta como possível cenário (Entrevistado 1 e OBS A).

Considerando a possibilidade do turismo interno se consolidar no mercado brasileiro, o Ministério do Turismo, na postagem MTUR 1, salientou que durante a pandemia" haverá financiamentos para micro, pequenos e médios empresários", tal aspecto também fomenta uma política pública de compromisso de recursos financeiros para manutenção de incentivo do turismo interno das GTs nacionais. Outro aspecto que merece ser apontado se constitui na concesão, via Fungetur, de empréstimos com taxas diferenciadas durante a pandemia. Assim como, os MEI e guias de turismo, cadastrados no Cadastur, estão sendo beneficiados (postagem MTUR 2 e 3).

Segundo a Medida Provisória 936, "o governo se comprometeu durante a pandemia a dar auxílio financeiro; acesso ao seguro-desemprego; e flexibilização do horário de trabalho" todas estas medidas visam garantir 8,5 milhões de empregos neste setor, gerando a capacidade de motivação dos atores de permanecerem neste ramo, fazendo com que os princípios de equidade entre os atores possam ser mantidos (postagem MTUR 8 e MTUR 9). Um ponto interessante analisado foi de que a COVID-19 trouxe impactos positivos na sustentabilidade do planeta (OBS L). Os mares ficaram menos poluídos, o ar ficou mais puro e animais silvestres voltaram a circular em áreas como os canais de Veneza, algo nunca esperado.

"Enquanto o turismo está sendo afetado, o meio ambiente agradece" segundo a Entrevistada 3. Novos aspectos começam a ser repensados, inclusive como um momento de oportunidades. Por exemplo, a mudança do paradigma dominante no atual modelo de turismo (Turismo de Massa), com seu viés predominantemente econômico, sendo esta uma nova delimitação na GT mundial, tal aspecto corrobora com os estudos de Queiroz e Horillo (2015). Neste aspecto as comunidades receptoras poderão acentuar a repulsa/negação à prática da atividade turística (overtourism), aumentando a relevância do papel da governança na gestão do destino turístico (OBS A e OBS L).

É fato que o turismo pós pandemia não será mais o mesmo, e que a competitividade será altíssima. "Penso, que todos os destinos do mundo estarão correndo para atrair turistas, acirrando a competitividade, inclusive por meio de estratégias como preço baixo" (Entrevistado 4). Este aspecto fomento o princípio apontado por Tomio e Schmidt (2014) onde a valorização de troca de informações e de experiências entre os atores dos empreendimentos coletivos deve ocorrer. Neste sentido, os destinos turísticos precisarão se articular, dando espaço a um processo mais democrático, transparente, eficaz, eficiente e efetivo, no qual, a 
união, a criatividade e o comprometimento dos diversos atores se evidenciam e geram vantagem competitiva (OBS A).

A promoção da Governança Turística também foi apontada como estratégia fundamental neste processo, tanto em nível nacional, quanto internacional, torna-se essencial, sendo as ações futuras pautadas em investir em experiências de qualidade, políticas que visem qualificar a oferta de serviços e ações que subsidiem a introdução de novas tecnologias, buscando inovar para que no futuro possa se ter um maior controle e previsões de casos/crises parecidas (Entrevistada 2 e OBS L). Tal aspecto, converge com o que aponta Queiroz e Horillo (2015) fomentando que as dimensões e delimitações de uma GT devem ser amparados por mecanismos de divulgações, websites, fóruns dentre outros.

Apesar das incertezas, o fato é que o momento é propício para a geração de conhecimentos, conteúdos gratuitos, planejamento, interações digitais, entre outras estratégias. Além da gestão mais ampla do marketing digital, aspectos legais (direito do consumidor), questões sanitárias, entre outras, serão fundamentais na retomada do Turismo pós COVID-19 (OBS J). Os empresários do setor precisarão inovar, investir em eventos, diversificar seus segmentos de atuação, se reinventar para ganharem em competitividade, inclusive, aqueles que possuem uma boa reputação online e habilidade em marketing digital tendem a sair na frente nesta corrida pela retomada dos negócios e da economia (Entrevistado 5 e OBS C). Neste sentido, a GT integrada poderá promover aumento de competitividade no setor turístico durante e pós COVID-19, promovendo um turismo consciente e fazendo com que todos os atores possam atuar de forma conjunta, integrada e com protagonismo, na busca da construção coletiva do turismo.

\section{CONSIDERAÇÕES FINAIS}

Este estudo buscou analisar a conjuntura das GTs no Brasil no contexto da COVID-19, e ele apontou alguns achados interessantes. Observando os aspectos vinculados aos princípios pode-se perceber que apesar de diversos dados apontarem a fragilidade da Política Pública Brasileira voltada ao Turismo e do mesmo ser basicamente uma política de governo e não de estado, com diversas mudanças de diretores e muitas vezes até fragilizadas pelo contexto político, o Ministério do Turismo através da MP 936, liberou R\$ 51 bilhões para a manutenção de empregos no setor turístico, durante a pandemia da COVID-19, através de empréstimos e, até mesmo, destinação de recursos para profissionais autônomos vinculados ao Cadastur, isto fez com que diversas empresas e empregos pudessem ser preservados. Isto pode corroborar com os estudos de Gonzalez (2014) demonstrando a importância das políticas públicas em governanças turísticas.

Observando aspectos voltados as dimensões e delimitações verificamos mecanismos de controles normativos emitidos pelo Ministério do Turismo, que pudesse garantir através do Selo de Turismo Responsável, Limpo e Seguro que o local é um lugar seguro e limpo para os turistas, garantindo assim, uma maior segurança ao viajante, durante a pandemia da COVID-19. Interessante ressaltar que tal Selo é válido para todas as GTs brasileiras, seguindo as premissas de Stoffelen e Vanneste (2017) que fomentam que uma GT não pode ser vista como um processo fácil e simples, mas como uma combinação institucional multiescalar, devendo possuir simetrias informacionais e alto reconhecimento de todos os stakeholders envolvidos.

É certo que o contexto pandêmico foi altamente prejudicial a todo o trade turístico, mas o benefício da sustentabilidade e melhora ecológica do planeta são incontestáveis, 
fazendo com que seja pauta de discussão nas GTs brasileiras a questão do turismo de massa ou overtourism, podendo até ser considerado uma nova delimitação e dimensão turística. É certo, que talvez agora seja um momento de rever os conceitos e ser verificado até que ponto este turismo predatório é realmente economicamente interessante.

Outro achado da pesquisa relacionado as dimensões turísticas, diz respeito ao desenvolvimento do turismo local, sendo um fator em voga, onde a GT possui todos os subsídios para auxiliar e desenvolver todas as suas particularidades, fazendo com que cada região possa mostrar o que de mais belo possui, como fomentado por Conceição (2020), a governança regional de turismo tem como função primordial atuar em prol de sua região de forma coesa, em que seus atores cooperem e realizem ações conjuntas e transparentes para melhoramento e desenvolvimento de suas regiões.

Por fim, esta pesquisa apontou também que o trade turístico deve agir de modo altamente competitivo, sendo este um princípio fundamental na GT para aliar esforços com a coesão de todos os atores envolvidos, com a utilização de divulgações onlines, tecnologias informacionais e a união para destinos integrados. Corroborando que as GTs devem ter soluções inovadoras, com maior transparência, que visam resolver problemas econômicos e sociais voltados ao turismo dentro de cada contexto (NUNKOO, 2015; UPADHYA, 2016).

Na perspectiva gerencial, o estudo contribui com a discussão sobre GT, importante lacuna na turismologia, evidenciando que sua ideia básica é fortalecer a cooperação e as relações de interação entre os atores do setor turístico. Dentre estes, atores públicos, privados e não governamentais, fundamentando-se nos governos, nas empresas com fins lucrativos, nas sem fins lucrativos (inclusive institutos de pesquisa), nos cidadãos, nos turistas e nos trabalhadores (os quais muitas vezes são representados por seus sindicatos). Evidenciou-se ainda, os seis princípios fundamentais da GT, que consistem em integridade, busca de equidade e proteção igualitária dos atores, visão e liderança, desenvolvimento de conhecimento e partilha de experiências, clareza de papéis e responsabilidades, e transparência e prestação de contas. Todas estas são diretrizes importantes aos gestores destas GT's.

Esta pesquisa teve como limitação o curto espaço de tempo de observação e coleta de dados devido ao recente contexto da COVID-19 no Brasil. Pesquisas futuras são sugeridas nesta temática, principalmente envolvendo estudos em GTs nacionais e internacionais no contexto da COVID-19, assim como fatores vinculados aos princípios, dimensões e delimitações de uma GT.

\section{REFERÊNCIAS}

AMÂNCIO-VIEIRA, S. F. A.; COSTA, B. K.; CINTRA, R. F. Stakeholders analysis: um novo campo de pesquisa no turismo. Revista Brasileira de Pesquisa em Turismo, v. 6, n. 2, p. 21-33, 2012. DOI: https://doi.org/10.7784/rbtur.v6i2.498.

BARBARÁ, S.; LEITÃO, M. C. S; FONTES FILHO, J. R. A Governança Regional em Turismo: realidade? Estudo de caso sobre o destino Estrada Real. Cadernos Ebape, v. 5, n. 4, p. 1-16, 2007. Disponível em:

http://bibliotecadigital.fgv.br/ojs/index.php/cadernosebape/article/view/5054. Acesso em: 20 jun. 2020. 
BÁRCIA, L. C. Governança turística da cidade de Búzios: um estudo sobre um potencial destino turístico inteligente. Revista Iberoamericana de Turismo, v. 10, p. 172-201, 2020. DOI: $10.2436 / 20.8070 .01 .172$.

BERNARDO, E. Planejamento turístico e impactos percebidos na ilha de Boa Vista, Cabo Verde. Turismo em Análise, v. 26, n. 4, p. 817-842, 2015. DOI: http://dx.doi.org/10.11606/issn.1984-4867.v26i4p817-842.

BERITELLI, P.; BIEGER, T.; LAESSER, C. Destination governance: Using corporate governance theories as a foundation for effective destination management. Journal of Travel Research, v. 46, n. 1, p. 96-107, 2007. DOI: https://doi.org/10.1177\%2F0047287507302385.

CARLISLE, S.; KUNC, M.; JONES, E.; TIFFIN, S. Supporting innovation for tourism development throught multi-stakeholder approaches: experiences from Africa. Tourism Management, v. 35, p. 59-69, 2013. DOI: https://doi.org/10.1016/j.tourman.2012.05.010.

CARVALHO, K. D. Lugar de memória e políticas públicas de preservação do patrimônio: Interfaces com o turismo cultural. Revista Turismo Visão e Ação - Eletrônica, v. 13, n. 2, p. 149-165, 2011. DOI: https://doi.org/10.14210/rtva.v13n2.p149-165.

CASCELLA, M.; RAJNIK, M.; CUOMO, A.; DULEBOHN, S. C.; DI NAPOLI, R. Features, Evaluation and Treatment Coronavirus (COVID-19). Disponível em: https://pubmed.ncbi.nlm.nih.gov/32150360/. Acesso em: 20 de jun. 2020.

CINTRA, R. F., AMÂNCIO-VIEIRA, S. F.; GONCALVES, L. P.; COSTA, B.Q. Turismo Local de Londrina-PR: Análise A Partir Da Teoria Do Stakeholder. Revista Contextus, v. 13, n. 2, p. 149-175, 2015b. DOI: https://doi.org/10.19094/contextus.v13i2.680.

CNC - Confederação Nacional de Comércio. Em 15 dias, COVID-19 provoca perdas de R\$2,2 bi no turismo. Publicado em 19/03/2020. Acesso em 24/04/2020. Disponível em:

http://cnc.org.br/editorias/economia/noticias/cnc-em-15-dias-COVID-19-provoca-perda-der-22-bi-no-turismo. Acesso em: 20 jun. 2020.

CONCEIÇÃO, C. C. Modelo analítico de governança regional de turismo - MAGRET. Revista Brasileira de Pesquisa em Turismo, v. 14, n. 2, p.123-139, 2020. DOI:

https://doi.org/10.7784/rbtur.v14i2.1822.

CORREIA, R. R.; ALPERSTEDT G. D.; FEUERSCHUTTE S. G. O uso do método netnográfico na pós-graduação em administração no Brasil. Revista de Ciências da Administração, v.19, n. 47, p. 163-175, 2017. DOI: https://doi.org/10.5007/2175-8077.2017v19n47p163.

CRODA, J.H.R.; GARCIA, L.P. Resposta imediata da Vigilância em Saúde à epidemia da COVID19. Epidemiologia e Serviços de Saúde, v. 29, p. 1-3, 2020. DOI: 10.5123/S167949742020000100021. 
DURAN, C. Governance for the tourism sector and its measurement. UNWTO Statistics and TSA Issue Paper Series STSA/IP/2013/01, p. 1-42, 2013.

DOI: https://doi.org/10.18111/9789284415632.

ESTOL, J.; FONT, X. European tourism policy: Its evolution and structure. Tourism Management, v. 52, n. 1, p. 230-241, 2016. DOI:

https://doi.org/10.1016/j.tourman.2015.06.007.

FERNANDES, L. M. M; CORIOLANO, L. N. M. T. A governança na política nacional de regionalização do turismo: Estudo dos grupos gestores dos destinos indutores do Ceará. Revista Turismo - Visão e Ação. Balneário Camboriú/SC v. 17, n. 2, p. 247-278, 2015. DOI: 10.14210/rtva.v17n2.p247-278.

FERNÁNDEZ, J. I.; FERNÁNDEZ, M. C. Proposal for an indicators system of tourism governance at tourism destination level. Social Indicators Research. Cham, Switzerland, p. 149, 2017. DOI: https://doi.org/10.1007/s11205-017-1627-z.

FERNANDEZ, J. I. P.; GARCIA, J. C. Tourism as an economic development tool. Key Factors. Current Issues in Tourism, Londres, p. 2082-2108, 2017. DOI: $10.1080 / 13683500.2017 .1420042$.

FRATUCCI, A. C. Refletindo sobre a gestão dos espaços turísticos: perspectivas para as redes regionais de turismo. Revista Turismo em Análise, v. 20, n. 3, 2009. DOI: 14192/16010.

FREEMAN, R. E.; HARRISON, J. S.; WICKS, A. C.; PARMAR, B. L.; COLLE, S. Stakeholder theory: the state of the art. The Academy of Management. Anais, v. 4, n. 1, p. 403-445, 2010. DOI: 10.1080/19416520.2010.495581.

FUINI, L. L. Circuitos turísticos no Brasil: governança e políticas públicas. Revista Geográfica Venezola, Mérida, Venezuela v. 55, n. 1, p. 45-67, 2014. DOI: http://www.saber.ula.ve/handle/123456789/38969.

FUNDAÇÃO GETÚLIO VARGAS - FGV Impacto Econômico do COVID-19: Propostas para o Turismo Brasileiro. FGV Projetos. Disponível em:

https://fgvprojetos.fgv.br/sites/fgvprojetos.fgv.br/files/01.covid19_impactoeconomico_v05. pdf. Acesso em: 20 maio 2020.

GENG Y., MAIMAITURXUN M., ZHANG, H. Coupling Coordination of Water Governance and Tourism: Measurement and Prediction. Hindawi, p. 2-13, 2020. DOI: https://doi.org/10.1155/2020/3683918.

GONZÁLEZ, M. V. Gobernanza turística: ¿Políticas públicas innovadoras a retórica banal? Caderno Virtual de Turismo. Edição especial: Hospitalidade e Políticas Públicas em Turismo, v. 14, n. 1, p. 9-22, 2014. Disponível em: www.ivt.coppe.ufrj.br/caderno. Acesso em: 20 maio 2020. 
HALL, C. M., SCOTT D., GOSSLING S. Pandemics, Transformations and Tourism: be careful what you wish for. Tourism Geographies, p. 1-22, 2020.

DOI: $10.1080 / 14616688.2020 .1759131$.

HARGUINDÉGUY, J. B. Análisis de políticas públicas. Ed. Tecnos. Madrid. 2013.

HUBNER, A.; PHONG, L. T.; CHÂU, T. S. H. Good governance and tourism development in protected areas: The case of Phong Nha-Ke Bang National Park, central Vietnam. Original Research. Koedoe, v. 56, n. 2, p. 1-10, 2014.

DOI: https://doi.org/10.4102/koedoe.v56i2.1146.

KALBASKA, N.; JANOWSKI, T.; ESTEVEZ, E.; CANTONI, L. When digital government matters for tourism: a stakeholder analysis. Information Technology and Tourism, v. 17, n. 3, p. 315333, 2017. DOI: https://doi.org/10.1007/s40558-017-0087-2.

KOZINETS, R. V. Netnografia: Realizando pesquisa etnográfica online. Porto Alegre: Penso, 2014.

LAZZARINI, S. G.; MUSACCHIO, A. O Leviatã como uma cura parcial? Oportunidades e armadilhas no uso do aparato estatal para responder à crise da COVID-19. Revista de Administração Pública, v. 54, n. 4, p. 561-577, 2020. DOI: 10.1590/0034-761220200120.

LOPES, P. M. A fraternidade em debate: percurso de estudos na América Latina. São Paulo, Editora Cidade Nova, 2012.

LUTHE, T.; WYSS, R. Resilience to climate change in a cross-scale tourism governance context: a combined quantitative-qualitative network analysis. Ecology \& Society, vol. 21 Issue 1, p167-184. 18p. 3 Diagrams, 5 Charts, 1 Map, 2016. DOI:

http://dx.doi.org/10.5751/ES-08234-210127.

MILLER, G.; RATHOUSE, K.; SCARLES, C.; HOLMES, K.; TRIBE, J. Public understanding of sustainable tourism. Annals of Tourism Research, vol. 37, N. 3, pp. 627-645, 2010. DOI: https://doi.org/10.1016/j.annals.2009.12.002.

MINISTÉRIO DO TURISMO [@MTur] (15 de abril de 2020). MTur, Empréstimos. Instagram: https://www.instagram.com/p/B_ANrhSnUTU/ Acesso: 29 de jul. de 2020.

MINISTÉRIO DO TURISMO [@MTur] (15 de abril de 2020). MTur, Medidas a juros baixos. Instagram: https://www.instagram.com/p/B_ANzuHHZDW/. Acesso: 29 de jul. de 2020.

MINISTÉRIO DO TURISMO [@MTur] (15 de abril de 2020). MTur, Medidas a juros baixos. Instagram: https://www.instagram.com/p/B_AN6oLn307/ Acesso: 29 de jul. de 2020.

MINISTÉRIO DO TURISMO [@MTur] (16 de abril de 2020). MTur, MP 936. Instagram: https://www.instagram.com/p/B_CzHtdHV5p/ Acesso: 29 de jul. de 2020. 
MINISTÉRIO DO TURISMO [@MTur] (16 de abril de 2020). MTur, MP 936. Instagram: https://www.instagram.com/p/B_CzWI_HEt5/ Acesso: 29 de jul. de 2020.

MINISTÉRIO DO TURISMO [@MTur] (16 de abril de 2020). MTur, MP 936. Instagram: https://www.instagram.com/p/B_Czbk4nBJF/ Acesso: 29 de jul. de 2020.

MINISTÉRIO DO TURISMO [@MTur] (09 de junho de 2020). MTur, Protocolos. Instagram: https://www.instagram.com/p/CBOKLCFHnJ_ Acesso: 29 de jul. de 2020.

MINISTÉRIO DO TURISMO [@MTur] (09 de junho de 2020). MTur, Protocolos. Instagram: https://www.instagram.com/p/CBOKQOXHQif/ Acesso: 29 de jul. de 2020.

MINISTÉRIO DO TURISMO [@MTur] (09 de junho de 2020). MTur, Protocolos. Instagram: https://www.instagram.com/p/CBOKQOXHQif/ Acesso: 29 de jul. de 2020.

MINISTÉRIO DO TURISMO MRT Mapa de Regionalização do Turismo. Ministério do Turismo: Brasília, 2009.

MINISTÉRIO DO TURISMO. PRT Programa de regionalização do turismo - roteiros do Brasil. Brasília, 2009. Disponível em:

http://institucional.turismo.gov.br/regionalizacao/arqreg/doc_download/Monitoria_Avaliac ao_vers ao_final.pdf. Acesso em: 05 fev. 2019.

NUNKOO, R. Tourism development and trust in local government. Tourism Management, v. 46, n. 1, pp. 623-634, 2015. DOI: 10.1016/j.tourman.2014.08.016.

ORGANIZAÇÃO MUNDIAL DA SAÚDE - OMS. Disponível em: https://www.who.int/eportuguese/countries/bra/pt/. Acesso em: 24 maio 2020.

ORGANIZAÇÃO PAN-AMERICANA DE SAÚDE - OPAS. Disponível em: https://www.paho.org/bra/. Acesso em: 21 de jun. 2020.

PECHLANER, H.; VOLGGER, M.; HERNTREI, M. Destination management organizations as interface between destination governance and corporate governance. Anatolia, v. 23, n. 2, p. 151-168, 2012. DOI: https://doi.org/10.1080/13032917.2011.652137.

PORTAL DE NOTÍCIAS UOL. Mortes por Coronavírus. Disponível em: https://noticias.uol.com.br/ultimas-noticias/reuters/2020/03/11/mortes-por-coronavirusem-um-dia-na-italia-saltam-31-e-acumulado-no-pais-vai-a-827.htm. Acesso em: 4 de jun. 2020.

QUEIROZ, F.; HORRILLO, R. M. A. El estado del arte en gobernanza de destinos turísticos. Tourism \& Management Studies, v. 11, n. 2, p. 47-55, 2015. DOI: 10.18089/tms.2015.11206.

RAICH, F. Governance räumlicher Wettbewerbseinheiten. Ein Ansatz für die TourismDestination. Wiesbaden: DUV, p. 83-144, 2006. DUV. https://doi.org/10.1007/978-3-83509445-1_3. 
RIBARIÉ, R. Drivers of innovation in sustainable tourism development: The conept and case of Istria destination. Tourism in Southrn and Eastern Europe, v. 3, p. 325-339, 2015. Disponível em: https://ssrn.com/abstract=2637367. Acesso em: 04 jun. 2020.

RICHARDSON, R. J. Pesquisa social: Métodos e técnicas. São Paulo: Atlas, 3 ed., 2008.

ROBERTSON, J. P. An assessment of collaborative governance in a network for sustainable tourism: the case of RedeTuris. International Journal of Public Administration, v. 34, n. 5, 279-290, 2011. DOI: https://doi.org/10.1080/01900692.2010.550078.

RODRIGUES, S. L.; SOUZA, M. The role of governance in the regionalization of tourism. Revista Brasileira de Ecoturismo, São Paulo, v. 8, n. 2, p. 234-250, 2015. DOI: https://doi.org/10.34024/rbecotur.2015.v8.6418.

RODRIGUES, V. G.; BERNARDO, E.; DOMINGUEZ, C. Public tourism framework in the Douro region: tourism governance in perspective. THIJ - Tourism and Hospitality International Journal, v. 10, n. 1, p. 1-166, 2018. Disponível em: https://thijournal.isce.pt/index.php/THIJ/issue/view/20/25/. Acesso em: 04 jun. 2020.

RUHANEN, L.; SCOTT, N.; RITCHIE, B.; TKACZYNSKI, A. Governance: a review and synthesis of the literature. Tourism Review, v. 65, n. 4, p. 4-16, 2010. DOI: https://doi.org/10.1108/16605371011093836.

SADE-BECK, L. Internet ethnography: online and offline. International Journal of Qualitative Methods, v. 3, n. 2, p. 1-14. Disponível em: http://ijq.sagepub.com/ content/3/2/45.full.pdf+html. Acesso em: 16 jul. 2020.

SAMPIERI, R. H.; CALLADO, C. F.; LUCIO, M. P. Metodologia da Pesquisa. 5. ed. Porto Alegre: Penso, 2013.

SIAKWAH P., MUSAVENGANE R., LEONARDO L. Tourism Governance and Attainment of the Sustainable Development Goals in Africa. Tourism Planning \& Development, p. 2-29, 2019. DOI: https://doi.org/10.1080/21568316.2019.1600160.

STOFFELEN A.; IOANNIDES D.; VANNESTE D. Obstacles to achieving cross-border tourism governance: A multi-scalar approach focusing on the German-Czech borderlands. Annals of Tourism Research, Elsevier Publisher, Amsterdã, n. 64, p. 126-138, 2017. DOI: https://doi.org/10.1016/j.annals.2017.03.003.

STOFFELEN, A., VANNESTE, D. Tourism and cross-border regional development: insights in European contexts. European Planning Studies, v. 25, n. 6, p. 1013-1033, 2017. DOI: https://doi.org/10.1080/09654313.2017.1291585.

STRIELKOWSKI, W. International Tourism and COVID-19: Recovery Strategies for Tourism Organisations. Preprint. Researchgate. The New York Times. Disponível em: https://www.nytimes.com/2020/05/25/world/europe/spain-courts-coronavirus.html. Acesso em: 4 de jun 2020. DOI: 10.20944/preprints202003.0445.v1. 
TOMIO, M.; SCHMIDT, C. M. Governança e ações coletivas no Turismo Regional: A experiência dos empreendedores da região oeste do Paraná. Revista Turismo Visão e Ação, Balneário Camboriú/SC, v. 16, n. 3, 2014. DOI: 10.14210/rtva.v16n3.p710-739.

TRENTIN, F. Governança turística em destinos brasileiros: comparação entre Armação dos Búzios/RJ, Paraty/RJ e Bonito/MS. Revista Pasos, Espanha, v. 14, n. 3, p. 645-658, 2016. DOI: https://doi.org/10.25145/j.pasos.2016.14.042.

UNWTO - United Nations World Tourism Organization. Report on the progress of the reform of the organization (white paper). UNWTO, Madrid, 2011. Disponível em: https://www.eunwto.org/doi/epdf/10.18111/unwtogad.2011.1.p22m57t0415txng7. Acesso em: 20 de abr. 2020.

UNWTO - United Nations World Tourism Organization. Technology in tourism. Madrid, 2011. Disponível em: www2.unwto.org/publication/am-reports-vol-1-technology-tourism. Acesso em: 20 abr. 2020.

UPADHYA, A. Polity, policy and destination management: an exploratory study of political systems and management of tourism with special reference to the GCC countries. International Journal of Tourism Policy, v. 6, n. 3/4, p. 341-361, 2016. DOI: https://doi.org/10.1504/IJTP.2016.081530.

VALENTE, F.; DREDGE, D.; LOHMANN, G. Leadership and governance in regional tourism. Journal of Destination Marketing \& Management, Elsevier Publisher, v. 4, p. 127-136, 2015. DOI: https://doi.org/10.1016/j.jdmm.2015.03.005.

VELASCO, G. M. Gestión de destinos: ¿Gobernabilidad del turismo o gobernanza del destino? In: Ministerio de educación y ciencia de España. Plan nacional de I+D+I (20042007), 2007.

VELASCO, M. Entre el poder y la racionalidade: gobierno del turismo, política turística, planificación turística y gestión pública del turismo. Pasos. v. 14, n. 3, p. 577-594, 2016. DOI: 10.25145/j.pasos.2016.14.038.

VERDÚ, C. P.; CHICA, A. A.; GARCIA, F. J. F.; FERNANDES, O. A. S. La investigación cualitativa: Técnicas de investigación y análisis con ATLAS.TI. Ecuador. Pydlos Ediciones, 2015.

VERGARA, S. C. Projetos e relatórios de pesquisa em administração. 3. ed. São Paulo: Atlas, 2000.

VIEIRA, S. F. A.; COSTA, B. K.; BOAVENTURA, J. M. G. Análise de stakeholders aplicada a órgãos públicos. Revista de Ciências da Administração, Florianópolis/SC, v. 13, n. 31, p. 81110, 2011. DOI: 10.5007/2175-8077.2011v13n31p81. 
WAN, Y. K. P.; BRAMWELL, B. Political economy and the emergence of a hybrid mode of governance of tourism planning. Tourism Management, v. 50, n. 1, p. 316-327, 2015. DOI: https://doi.org/10.1016/j.tourman.2015.03.010.

WESLEY, A.; PFOOR, C. The governance of coastal tourism: unravelling the layers of complexity at Smiths Beach, Westearn Australia. Journal of Sustanaible Tourism, v. 18, n. 6, p. 773-792, 2010. DOI: https://doi.org/10.1080/09669581003721273.

WORLD TRAVEL TOURISM COUNCIL - WTTC (2020). Coronavirus Brief. WTTC, ed WTTC, v. 1, 2020.

YIN, R. K. Pesquisa qualitativa: do início ao fim. Porto Alegre: Penso, 2016. 